\title{
Combined impact of healthy lifestyle factors on colorectal cancer: a large European cohort study
}

Krasimira Aleksandrova ${ }^{1 *}$, Tobias Pischon ${ }^{2}$, Mazda Jenab $^{3}, \mathrm{H}$ Bas Bueno-de-Mesquita ${ }^{4,5,6}$, Veronika Fedirko ${ }^{3,7}$, Teresa Norat ${ }^{6}$, Dora Romaguera ${ }^{6,8,9}$, Sven Knüppel ${ }^{1}$, Marie-Christine Boutron-Ruault ${ }^{10,11,12}$, Laure Dossus ${ }^{10,11,12}$, Laureen Dartois $^{10,11,12}$, Rudolf Kaaks ${ }^{13}$, Kuanrong Li ${ }^{13}$, Anne Tjønneland ${ }^{14}$, Kim Overvad ${ }^{15}$, José Ramón Quirós ${ }^{16}$, Genevieve Buckland ${ }^{17}$, María José Sánchez ${ }^{18,19}$, Miren Dorronsoro ${ }^{20}$, Maria-Dolores Chirlaque ${ }^{19,21}$, Aurelio Barricarte ${ }^{22}$, Kay-Tee Khaw ${ }^{23}$, Nicholas J Wareham ${ }^{24}$, Kathryn E Bradbury ${ }^{25}$, Antonia Trichopoulou 26,27, Pagona Lagiou ${ }^{27,28}$, Dimitrios Trichopoulos ${ }^{27,28,29}$, Domenico Palli ${ }^{30}$, Vittorio Krogh ${ }^{31}$, Rosario Tumino ${ }^{32}$, Alessio Naccarati ${ }^{33}$, Salvatore Panico ${ }^{34}$, Peter D Siersema ${ }^{5}$, Petra HM Peeters ${ }^{6,35}$, Ingrid Ljuslinder ${ }^{36}$, Ingegerd Johansson ${ }^{37}$, Ulrika Ericson ${ }^{38}$, Bodil Ohlsson ${ }^{39}$, Elisabete Weiderpass ${ }^{40,41,42,43}$, Guri Skeie ${ }^{40}$, Kristin Benjaminsen Borch ${ }^{40}$, Sabina Rinaldi ${ }^{3}$, Isabelle Romieu ${ }^{3}$, Joyce Kong ${ }^{3}$, Marc J Gunter ${ }^{6}$, Heather A Ward ${ }^{6}$, Elio Riboli' ${ }^{6}$ and Heiner Boeing ${ }^{1}$

\begin{abstract}
Background: Excess body weight, physical activity, smoking, alcohol consumption and certain dietary factors are individually related to colorectal cancer (CRC) risk; however, little is known about their joint effects. The aim of this study was to develop a healthy lifestyle index (HLI) composed of five potentially modifiable lifestyle factors healthy weight, physical activity, non-smoking, limited alcohol consumption and a healthy diet, and to explore the association of this index with CRC incidence using data collected within the European Prospective Investigation into Cancer and Nutrition (EPIC) cohort.
\end{abstract}

Methods: In the EPIC cohort, a total of 347,237 men and women, 25- to 70-years old, provided dietary and lifestyle information at study baseline (1992 to 2000). Over a median follow-up time of 12 years, 3,759 incident CRC cases were identified. The association between a HLI and CRC risk was evaluated using Cox proportional hazards regression models and population attributable risks (PARs) have been calculated.

Results: After accounting for study centre, age, sex and education, compared with 0 or 1 healthy lifestyle factors, the hazard ratio (HR) for CRC was 0.87 (95\% confidence interval (Cl): 0.44 to 0.77 ) for two factors, 0.79 (95\% Cl: 0.70 to 0.89 ) for three factors, 0.66 ( $95 \% \mathrm{Cl}: 0.58$ to 0.75 ) for four factors and 0.63 ( $95 \%$ Cl: 0.54 to 0.74 ) for five factors; $P$-trend $<0.0001$. The associations were present for both colon and rectal cancers, HRs, 0.61 (95\% Cl: 0.50 to 0.74; $P$ for trend <0.0001) for colon cancer and 0.68 ( $95 \% \mathrm{Cl}: 0.53$ to 0.88; $P$-trend $<0.0001)$ for rectal cancer, respectively ( $P$-difference by cancer sub-site $=0.10)$. Overall, $16 \%$ of the new CRC cases ( $22 \%$ in men and $11 \%$ in women) were attributable to not adhering to a combination of all five healthy lifestyle behaviours included in the index.

Conclusions: Combined lifestyle factors are associated with a lower incidence of CRC in European populations characterized by western lifestyles. Prevention strategies considering complex targeting of multiple lifestyle factors may provide practical means for improved CRC prevention.

Keywords: lifestyle factors, combined impact, population attributable risks, colorectal cancer, European Prospective Investigation into Cancer and Nutrition (EPIC)

\footnotetext{
* Correspondence: krasimira.aleksandrova@dife.de

'Department of Epidemiology, German Institute of Human Nutrition

Potsdam-Rehbrücke, Nuthetal, Germany

Full list of author information is available at the end of the article
} 


\section{Background}

Colorectal cancer (CRC) is the third most common cancer in men $(746,000$ cases per year, $10.0 \%$ of the total cancer incidence) and the second in women $(614,000$ cases per year, $9.2 \%$ of the total cancer incidence) worldwide [1]. There is a wide geographical variation in CRC incidence rates across the world with almost $55 \%$ of the cases occurring in more developed regions [1]. The parallel between the cancer frequency rates and the level of 'westernisation' points to an important role of lifestyle factors in the etiology of CRC [2-13]. In support of this hypothesis, the World Cancer Research Fund/American Institute for Cancer Research (WCRF/AICR) expert panel acknowledged that high physical activity and high intakes of dietary fibre, fish, nuts, dairy products, and fruits and vegetables are associated with a lower CRC risk, whereas high body mass index (BMI) and waist circumference, smoking, alcohol consumption, and red and processed meat intakes are related to a higher CRC risk [14-16]. While individual roles of these lifestyle factors have been extensively investigated, little is known about their joint effects. Most epidemiological studies explored individual health behaviours by treating other lifestyle factors as covariates in statistical models; however, in real life it is uncommon that people practice isolated behaviours. A multidimensional lifestyle approach would be more informative for exploring disease etiology, as well as for translating epidemiological findings into meaningful prevention strategies. Furthermore, estimation of health impact measures, such as population attributable risks (PARs), may provide better means for public health decision making, because PARs address what proportion of disease risk may be prevented over a specified time interval if a risk factor (or a combination of risk factors) is absent in a given population [17]. In addition, differences between colon and rectal anatomical cancer subtypes and sex have been previously shown to exist for associations with several lifestyle factors, such as excess body weight, waist circumference and physical inactivity [18-20]; however, it is not clear whether such differences may be valid also for combinations of factors. Finally, varying combinations of risk factors differentially contribute to diabetes, cardiovascular diseases and cancer overall [21]; therefore, it may be important to investigate specific lifestyle patterns in relation to CRC risk. To address these aspects, we aimed to develop a healthy lifestyle index (HLI) composed of five potentially modifiable lifestyle factors - healthy weight, physical activity, nonsmoking, limited alcohol consumption and a healthy diet - and to explore the association of this index with CRC incidence using data collected within the European Prospective Investigation into Cancer and Nutrition (EPIC) cohort. Furthermore, we aimed to evaluate the combined impact of these lifestyle factors in terms of PARs overall and according to colon and rectal cancer anatomical sub-site and by sex.

\section{Methods}

\section{Study design and population}

A total of 521,330 men and women, 25- to 70-years old, were recruited between 1 January 1992 and 31 December 2000 from 23 centres in 10 European countries: Denmark, France, Germany, Greece, Italy, the Netherlands, Norway, Spain, Sweden and the United Kingdom. Approval for the EPIC study was obtained from the ethical review boards of the International Agency for Research on Cancer and from all local institutions where subjects had been recruited for the EPIC study [see Additional file 1: Table S1]. Written informed consent was obtained from all participants before joining the EPIC study. Details of the recruitment and study design have been published elsewhere [22]. We excluded participants with missing data on dietary factors $(n=6,193)$, waist circumference measurements ( $\mathrm{n}=109,302)$, smoking history $(11,746)$, physical activity ( $\mathrm{n}=69,393)$, underweight participants (BMI <18; $\mathrm{n}=$ 95,381) and participants with prevalent diabetes reported at study baseline $(n=13,049)$. Due to missing data on waist circumference measurements, participants from Norway $(n=35,890)$ were excluded from the analyses. Consequently, the study population for the current analyses was comprised of 3,759 CRC cases (2,369 colon cancers and 1,390 rectal cancers) and 343,478 non-cases.

\section{Case ascertainment}

Cancer cases were identified through population cancer registries in Denmark, Italy, the Netherlands, Spain, Sweden and the United Kingdom. In France, Germany and Greece, a combination of methods was used including health insurance records, cancer pathology registries and active follow-up of study participants and their next of kin. Follow-up began at the date of enrolment and ended at the date of diagnosis of cancer, death or last complete follow-up. The last update of endpoint information was done up to 31 September 2010. Cancer incidence data were coded according to the 10th revision of the International Statistical Classification of Diseases, Injuries and Causes of Death [23] and the second revision of the International Classification of Diseases for Oncology [24]. Only the first primary neoplasm was included in the analysis; non-melanoma skin cancer was excluded.

\section{Assessment of lifestyle factors}

At baseline, participants filled out extensive medical, dietary and lifestyle questionnaires, including questions on alcohol use, smoking status, physical activity, education and previous illnesses. Body weight, height and waist circumference were measured in all centres except for EPICOxford (health-conscious population) and France where 
anthropometric measurements were self-reported [22]. Usual food intakes were measured by using countryspecific validated dietary questionnaires, and individual nutrient intakes were derived from foods included in the dietary questionnaires through the standardised EPIC Nutrient Database [25]. All dietary variables used in the present study were calibrated by using an additive calibration method as previously described [26].

\section{HLI definition}

We generated the HLI based on a priori knowledge of the CRC risk factors [2-13] and available national and international public health recommendations (that is, WCRF/AICR (2007)) [15,16]. We used a binary score for each factor in order to allow easy translation of findings into a prevention practice (Table 1). Participants were assigned one point for each of the following behaviours assessed at study baseline: healthy weight (BMI <25 [27] or waist circumference $<80 \mathrm{~cm}$ for women and $<94 \mathrm{~cm}$ for men [28]); not smoking or former smoking, high physical activity [13], adherent to alcohol consumption recommendations of the WCRF/AICR (2007) [16] and having a healthy diet. Healthy diet was evaluated based on a dietary quality index including eight dietary factors (fruits, vegetables, red and processed meat, fibre, fish, nuts, garlic and yogurt), which were previously shown to be related to CRC [see Additional file 2: Table S2]. Finally, the HLI was constructed by summing the binary score for each of the five lifestyle factors which ranged from 0 (least healthy) to 5 (most healthy) points.

\section{Statistical analysis}

In descriptive analyses, we estimated the prevalence of each individual lifestyle factor included in the HLI and examined the baseline characteristics of the study participants according to an increasing HLI score. We next evaluated the association of the lifestyle factors modeled individually and in combination - as an index variable (HLI) - with risk of CRC. We used multivariable Cox proportional hazards models to calculate hazard ratios and 95\% confidence intervals (CIs). Age (continuous) was used as the primary time-dependent variable in all models, with entry time defined as the subject's age at recruitment (years) and exit time as the age at diagnosis, death or

Table 1 Description and prevalences of the factors comprising the Healthy Lifestyle Index (HLI), the EPIC Cohort (1992 to 2010)

\begin{tabular}{|c|c|c|c|c|c|}
\hline \multirow[t]{2}{*}{ Lifestyle factor } & \multirow[t]{2}{*}{$\begin{array}{l}\text { Index } \\
\text { points }\end{array}$} & \multirow[t]{2}{*}{ Description } & \multicolumn{3}{|c|}{$\begin{array}{l}\text { Prevalence in the EPIC study } \\
\text { population (\%) }\end{array}$} \\
\hline & & & Men & Women & Overall \\
\hline \multirow[t]{2}{*}{ Overweight and obesity $^{a}$} & 0 & $\begin{array}{l}\text { Overweight or obese: } \mathrm{BMI} \geq 25 \mathrm{~kg} / \mathrm{m}^{2} \text { or waist circumference } \geq 94 \mathrm{~cm} \text { for } \\
\text { men and } \geq 80 \mathrm{~cm} \text { for women }\end{array}$ & & & \\
\hline & 1 & $\begin{array}{l}\text { Healthy weight: BMI } 18 \text { to } 25 \mathrm{~kg} / \mathrm{m}^{2} \text { or waist circumference }<94 \text { for men } \mathrm{cm} \\
\text { and }<80 \text { for women }\end{array}$ & 52.2 & 62.1 & 58.6 \\
\hline \multirow[t]{2}{*}{ Physical activity $^{\mathrm{b}}$} & 0 & $\begin{array}{l}\text { Low and very low physical activity: sedentary or standing occupation and } \\
\text { recreational METs } \leq 57 \text { for men and METs } \leq 82 \text { for women }\end{array}$ & & & \\
\hline & 1 & $\begin{array}{l}\text { High and very high physical activity: manual or heavy manual occupation } \\
\text { and recreational METs }>57 \text { for men and METs }>82 \text { for women }\end{array}$ & 50.3 & 52.6 & 51.7 \\
\hline \multirow[t]{2}{*}{ Smoking } & 0 & Smoking: current smokers & & & \\
\hline & 1 & Non-smoking: never or former smokers & 69.1 & 79.8 & 76.1 \\
\hline \multirow[t]{2}{*}{ Alcohol consumption } & 0 & $\begin{array}{l}\text { Heavy alcohol consumption: not adherent to alcohol consumption } \\
\text { recommendations of WCRF/AICR (2007) [15] for two standard drinks a day } \\
\text { (>24 g/day) for men and one standard drink a day (>12 g/day) for women }\end{array}$ & & & \\
\hline & 1 & $\begin{array}{l}\text { Limited alcohol consumption: adherent to alcohol consumption } \\
\text { recommendations of WCRF/AICR (2007) [15,16] for two standard drinks a day } \\
\text { ( } \leq 24 \mathrm{~g} / \text { day) for men and one standard drink a day ( } \leq 12 \mathrm{~g} / \text { day) for women }\end{array}$ & 66.0 & 75.9 & 72.4 \\
\hline \multirow[t]{2}{*}{ Diet quality ${ }^{c}$} & 0 & $\begin{array}{l}\text { Unhealthy diet quality: } 0 \text { to } 4 \text { points of the diet index of colorectal cancer } \\
\text { related foods }\end{array}$ & & & \\
\hline & 1 & $\begin{array}{l}\text { Healthy diet quality: } 5 \text { to } 8 \text { points of the diet index of colorectal cancer } \\
\text { related foods }\end{array}$ & 60.9 & 59.6 & 60.1 \\
\hline \multicolumn{6}{|c|}{$\begin{array}{l}\text { Based on the World Health Organisation's standard cutoff point for overweight [27] or waist circumference }<80 \mathrm{~cm} \text { for women and }<94 \mathrm{~cm} \text { for men according to } \\
\text { the European Group for the Study of Insulin Resistance (EGIR) recommendations for European populations [28]. }{ }^{\circ} \mathrm{A} \text { MET is defined as the ratio of work metabolic } \\
\text { rate to a standard metabolic rate of } 1.0\left(4.184 \mathrm{~kJ}^{\mathrm{J}} \mathrm{kg}^{-1} \mathrm{~h}^{-1} ; 1 \mathrm{MET} \text { is considered a resting metabolic rate obtained during quiet sitting. The MET values assigned to }\right. \\
\text { the non-occupational data were } 3.0 \text { for walking, } 6.0 \text { for cycling, } 4.0 \text { for gardening, } 6.0 \text { for sports, } 4.5 \text { for home repair (do-it-yourself work), } 3.0 \text { for housework and } \\
8.0 \text { for stair climbing [13]. 'Healthy diet was evaluated based on a dietary quality index including eight dietary factors (fruits, vegetables, red and processed meat, } \\
\text { fibre, fish, nuts, garlic and yogurt), which were previously shown to be related to CRC overall and in the EPIC data [2-8,11,12,38-40] (Additional file 2, Table S2). } \\
\text { BMI, body mass index (calculated as weight in kilograms divided by height in squared metres); EPIC, European Prospective Investigation into Cancer and Nutrition; } \\
\text { METs, metabolic equivalents of energy expenditure (MET)-hours per week per year; WCRF/AICR, World Cancer Research Fund/American Institute for } \\
\text { Cancer Research. }\end{array}$} \\
\hline
\end{tabular}


return of the last follow-up questionnaire, whichever came first. Individual associations of the lifestyle factors with CRC were evaluated with each lifestyle factor modeled as a binary variable. The base model was stratified by EPIC study centre, and adjusted for age at study recruitment, sex (in the sex combined model) and educational level. The multivariable model for individual lifestyle factors was additionally adjusted for the remaining lifestyle factors. In these analyses, participants with 0 points (least healthy) were the reference group. To evaluate the association of the lifestyle factors in combination, we modeled the HLI both as an ordinal variable and as a categorical variable according to six categories ( 0 to 5 points) with the least healthy group ( 0 points) as the reference group. $P$-value for the linear trend was calculated using the Wald test treating the index as a continuous variable. Since normal body weight may be considered as a consequence of healthy lifestyle behaviours (that is, high physical activity and a healthy diet), we performed a subgroup analysis excluding participants with healthy weights ( 0 to 4 scores). In order to test whether individual factors may statistically explain the association between the combined index and $\mathrm{CRC}$, we added each of the factors to the multivariableadjusted model one at a time. The percent change in the regression coefficient with adjustment for each individual lifestyle factor was compared with the multivariable model. The corresponding 95\% CI was calculated based on Fieller's theorem [29]. In addition, we examined the multivariable risks of CRC according to all possible combinations of lifestyle factors. The five dichotomised healthy lifestyle factors yielded thirty two combinations and the hazard ratios (HRs) for each of these combinations were calculated using participants who had no healthy factors as the reference group. All analyses were performed separately for colon and rectal cancer and by sex. Differences by cancer site were tested by competing risk analyses using the model of Lunn-McNeil [30], whereas the differences by sex were tested based on the likelihood ratio test by generating cross-product terms in multivariable models. Under the assumption that the associations are causal, we calculated the percentage of PARs and 95\% CIs to estimate the proportion of CRC cases attributed to each individual lifestyle factor, as well as to lack of adherence to all of the five healthy lifestyle factors. For these analyses, we compared participants in the high-risk category with the rest of the population for each factor and for the index. PARs for single lifestyle factors were derived from equations by Miettinen [31] taking the strata specific prevalences of cases and multivariable-adjusted HRs into consideration. Attributable risks for factors in combination $\left(\mathrm{PAR}_{\mathrm{j}}\right)$ were determined using an equation by Bruzzi et al. [32]:

$$
P A R_{\mathrm{j}}=\rho_{\mathrm{j}} \frac{\mathrm{RR}_{\mathrm{J}}-1}{\mathrm{RRj}},
$$

where $\rho_{j}$ is the prevalence of individuals not in the low risk group and $\mathrm{RR}_{\mathrm{j}}$ is the associated multivariableadjusted hazard ratio. Upper and lower CIs of the PARs were calculated based on the formula by Whittemore et al. [33], as reported in previous analyses [34-36]. We stratified the analysis according to median age (52.4 years) and country in order to examine the potential of effect modification by any of these factors. In addition, we performed sensitivity analysis to account for possible influence on the associations of family history as an established risk factor for CRC using available data from the EPIC centres in France, Spain and the United Kingdom, where 5,309 participants have reported having a family history of CRC. We also performed analyses comparing participants with and without missing data on major lifestyle exposure variables in order to control for potential missing data bias. Finally, we performed a lag analysis excluding participants diagnosed with cancer within the first two years of study follow-up to control for potential influence of subclinical disease on these associations. All statistical analyses were performed using the Statistical Analysis System (SAS) (version 9.2), Enterprise Guide User Interface (version 4.3); SAS Institute, Inc., Cary, NC, USA. All $P$ values were based on two-sided tests, and $P<.05$ was considered statistically significant.

\section{Results and discussion}

The median follow-up time of the study was 12 years (5th to 95th centile: 7.0 to 14.5 ). The total cohort's median age was $51.8 \pm 10.2$ years, and 121,116 (35\%) of the participants were men. Among the study population, 203,595 (59\%) participants had BMI and waist circumference within the recommended range, 179,787 (52\%) had high physical activity, 264,153 (76\%) were nonsmokers (among these, 63\% had never smoked and 37\% were former smokers), 251,523 (72\%) had alcohol intake within the recommended limits, and 208,562 (60\%) had a healthy diet as assessed by the dietary quality index (Table 1). The participants having a higher HLI were more likely to be women and tended to have a higher educational level (Table 2). Each healthy lifestyle factor was associated with a reduction in CRC risk after taking age, sex, educational status and the remaining lifestyle factors into account (Table 3). Compared with participants with no or one healthy lifestyle factors, the multivariableadjusted HR for CRC was 0.87 (95\% CI: 0.76 to 0.98) for two factors, 0.79 (95\% CI: 0.70 to 0.89 ) for three factors, 0.66 (95\% CI: 0.58 to 0.75 ) for four factors and 0.63 (95\% CI: 0.54 to 0.74 ) for five factors; $P$-trend $<0.0001$ (Figure 1). When evaluated ordinally, each additional healthy lifestyle factor was associated with a $12 \%$ lower risk of CRC (HR for a one point increase on the index= 0.88; $95 \%$ CI: 0.86 to 0.92 ), $13 \%$ lower risk of colon cancer $(\mathrm{HR}=0.87 ; 95 \% \mathrm{CI}=0.83$ to 0.90$)$ and $9 \%$ lower risk of 
Table 2 Baseline characteristics of participants by Healthy Lifestyle Index (HLI) score, the EPIC cohort (1992 to 2010)

\begin{tabular}{|c|c|c|c|c|c|c|}
\hline \multirow[t]{2}{*}{ Characteristics } & \multicolumn{5}{|c|}{ Healthy lifestyle index points } & \multirow[b]{2}{*}{5} \\
\hline & 0 & 1 & 2 & 3 & 4 & \\
\hline Participants, number (\%) & $2,783(0.8)$ & $20,865(6.0)$ & $66,110(19.0)$ & $113,171(32.6)$ & $106,518(30.7)$ & $37,790(10.9)$ \\
\hline Colon cancer, number of cases & 28 & 188 & 526 & 816 & 602 & 209 \\
\hline Rectal cancer, number of cases & 12 & 121 & 326 & 459 & 348 & 124 \\
\hline Colorectal cancer, number of cases & 40 & 309 & 852 & 1275 & 950 & 333 \\
\hline \multicolumn{7}{|l|}{ Socio-demographic characteristics: } \\
\hline Age, mean, SD & 52.7 & 52.1 & 52.2 & 51.9 & 51.5 & 50.8 \\
\hline Men, $\%$ & 58.5 & 51.0 & 42.9 & 34.5 & 28.3 & 29.6 \\
\hline University degree, $\%$ & 21.4 & 22.8 & 22.9 & 23.6 & 24.1 & 25.5 \\
\hline \multicolumn{7}{|l|}{ Lifestyle factors: } \\
\hline BMl, $\mathrm{kg} / \mathrm{m}^{2}$ median & 28.1 & 27.4 & 26.7 & 25.6 & 24.5 & 23.5 \\
\hline \multicolumn{7}{|l|}{ Waist circumference, $\mathrm{cm}$, median } \\
\hline Men & 101.0 & 100.0 & 98.0 & 95.0 & 90.5 & 87.3 \\
\hline Women & 89.0 & 85.0 & 83.0 & 80.0 & 77.0 & 73.6 \\
\hline METs recreational and household activity & 44.8 & 54.1 & 66.5 & 81.3 & 98.8 & 122.8 \\
\hline Never or former smokers, $\%$ & - & 2.0 & 13.4 & 33.1 & 37.0 & 14.3 \\
\hline \multicolumn{7}{|l|}{ Alcohol consumption, grams/day, median } \\
\hline Men & 46.0 & 37.2 & 25.5 & 13.8 & 9.5 & 7.5 \\
\hline Women & 24.2 & 18.1 & 11.0 & 4.5 & 2.3 & 1.9 \\
\hline \multicolumn{7}{|l|}{ Dietary factors, grams/day, median } \\
\hline Fibre & 17.1 & 18.3 & 19.6 & 21.4 & 24.0 & 26.3 \\
\hline Fruits & 88.4 & 113.2 & 146.6 & 195.1 & 256.6 & 287.1 \\
\hline Vegetables & 107.3 & 120.4 & 136.3 & 165.6 & 216.4 & 245.7 \\
\hline Yoghurt & 4.1 & 8.9 & 16.2 & 24.5 & 40.1 & 53.6 \\
\hline Nuts & 0.66 & 0.69 & 0.82 & 0.82 & 1.60 & 2.33 \\
\hline Garlic & 6.9 & 6.8 & 6.6 & 7.7 & 12.6 & 16.0 \\
\hline Red and processed meat & 128.0 & 119.0 & 109.5 & 98.9 & 85.5 & 72.7 \\
\hline Fish & 17.5 & 17.5 & 17.9 & 19.7 & 22.8 & 24.0 \\
\hline
\end{tabular}

BMI, body mass index (calculated as weight in kilograms divided by height in squared meters); EPIC, European Prospective Investigation into Cancer and Nutrition; METs, metabolic equivalents of energy expenditure (MET)-hours per week per year; SD, standard deviation.

rectal cancer $(\mathrm{HR}=0.91 ; 95 \% \mathrm{CI}: 0.87$ to $0.95 ;$-difference by cancer sub-site $=0.10$; Table 4 ). Overall, the associations between HLI and CRC were stronger in men compared to women $(P$-interaction $=0.03)$; however, when stratified by cancer site it became obvious that these differences could be mostly observed for rectal cancer but not for colon cancer $(P$-interaction $=0.0008)$. Additional adjustment for each of the individual lifestyle factors did not materially change the associations of HLI with CRC [see Additional file 3: Table S3]. However, in analyses by cancer site and sex, overweight and obesity appeared to statistically significantly explain the association of HLI with colon cancer in men by $29 \%$ (95\% CI: $7 \%$ to $62 \%$ ). In analysis based on an index that excluded healthy weight, the associations remained similar (that is, HR for a one point increase on the index $=0.89 ; 95 \% \mathrm{CI}$ : 0.87 to 0.92 , for $\mathrm{CRC}$ ). The estimated PARs of CRC representing the percentage of the population attributable to nonadherence to the particular healthy lifestyle behaviour were $8 \%, 3 \%, 4 \%, 4 \%$ and $5 \%$ for healthy weight, physical activity, non-smoking, limited alcohol consumption and a healthy diet, respectively. Overall $16 \%$ of the new CRC cases $(22 \%$ in men and $11 \%$ in women) were attributable to not adhering to a combination of all of these five healthy lifestyle behaviours (Table 5). The results revealed a cancer-site and sex-specific gradient in estimated PARs such that $36 \%$ of rectal cancer cases in men and $20 \%$ of colon cancer cases in women were attributable to not adhering to all five healthy lifestyle factors, while no significant PARs were seen for colon cancer in men and rectal cancer in women. When we conducted analyses according to different combinations of two, three and four healthy lifestylefactors relative to no or one factors, we did not observe a lower risk for any of the combinations of two 
Table 3 Hazard ratios of colorectal cancer in relation to individual lifestyle factors, the EPIC cohort (1992 to 2010)

\begin{tabular}{|c|c|c|c|c|c|c|c|c|c|c|}
\hline \multirow[b]{2}{*}{ Healthy lifestyle factor } & \multirow[b]{2}{*}{ Index } & \multicolumn{3}{|c|}{ Colon cancer } & \multicolumn{3}{|c|}{ Rectal cancer } & \multicolumn{3}{|c|}{ Colorectal cancer } \\
\hline & & $\begin{array}{l}\text { Cases, } \\
\text { number }\end{array}$ & $\begin{array}{l}\text { Model } 1^{\mathrm{a}} \\
\text { HR }(95 \% \mathrm{Cl})\end{array}$ & $\begin{array}{l}\text { Model } 2^{\mathrm{b}} \\
\text { HR }(95 \% \mathrm{Cl})\end{array}$ & $\begin{array}{l}\text { Cases, } \\
\text { number }\end{array}$ & $\begin{array}{l}\text { Model } 1^{\mathrm{a}} \\
\text { HR }(95 \% \mathrm{Cl})\end{array}$ & $\begin{array}{l}\text { Model } 2^{b} \\
\text { HR }(95 \% \text { Cl) }\end{array}$ & $\begin{array}{l}\text { Cases, } \\
\text { number }\end{array}$ & $\begin{array}{l}\text { Model } 1^{\mathrm{a}} \\
\text { HR }(95 \% \mathrm{Cl})\end{array}$ & $\begin{array}{l}\text { Model } 2^{b} \\
\text { HR }(95 \% \text { Cl) }\end{array}$ \\
\hline \multicolumn{11}{|l|}{ All } \\
\hline \multirow[t]{2}{*}{ Overweight and obesity } & 0 & 1,231 & 1 (Ref.) & 1 (Ref.) & 671 & 1 (Ref.) & 1 (Ref.) & 1,902 & 1 (Ref.) & 1 (Ref.) \\
\hline & 1 & 1,138 & $0.80(0.73-0.87)$ & $0.80(0.74-0.87)$ & 719 & $0.93(0.84-1.03)$ & $0.92(0.82-1.03)$ & 1,857 & $0.84(0.79-0.90)$ & $0.84(0.79-0.90)$ \\
\hline \multirow[t]{2}{*}{ Physical activity } & 0 & 1,144 & 1 (Ref.) & 1 (Ref.) & 648 & 1 (Ref.) & 1 (Ref.) & 1,792 & 1 (Ref.) & 1 (Ref.) \\
\hline & 1 & 1,225 & $0.87(0.80-0.95)$ & $0.88(0.81-0.96)$ & 742 & $1.02(0.91-1.14)$ & $1.03(0.92-1.15)$ & 1,967 & $0.92(0.86-0.99)$ & $0.94(0.87-1.00)$ \\
\hline \multirow[t]{2}{*}{ Smoking } & 0 & 550 & 1 (Ref.) & 1 (Ref.) & 378 & 1 (Ref.) & 1 (Ref.) & 928 & 1 (Ref.) & 1 (Ref.) \\
\hline & 1 & 1,819 & $0.90(0.82-1.00)$ & $0.91(0.83-1.00)$ & 1,012 & $0.82(0.72-0.93)$ & $0.84(0.74-0.95)$ & 2,831 & $0.87(0.81-0.94)$ & $0.88(0.82-0.96)$ \\
\hline \multirow[t]{2}{*}{ Alcohol consumption } & 0 & 695 & 1 (Ref.) & 1 (Ref.) & 462 & 1 (Ref.) & 1 (Ref.) & 1,157 & 1 (Ref.) & 1 (Ref.) \\
\hline & 1 & 1,671 & $0.91(0.83-0.99)$ & $0.91(0.83-1.00)$ & 928 & $0.79(0.71-0.89)$ & $0.81(0.72-0.91)$ & 2,602 & $0.86(0.80-0.93)$ & $0.87(0.81-0.94)$ \\
\hline \multirow[t]{2}{*}{ Diet quality } & 0 & 1,084 & 1 (Ref.) & 1 (Ref.) & 629 & 1 (Ref.) & 1 (Ref.) & 1,713 & 1 (Ref.) & 1 (Ref.) \\
\hline & 1 & 1,285 & $0.86(0.79-0.94)$ & $0.88(0.81-0.96)$ & 761 & $0.87(0.78-0.98)$ & $0.89(0.79-1.01)$ & 2,046 & $0.86(0.81-0.93)$ & $0.88(0.83-0.95)$ \\
\hline \multicolumn{11}{|l|}{ Men } \\
\hline \multirow[t]{2}{*}{ Overweight and obesity } & 0 & 602 & 1 (Ref.) & 1 (Ref.) & 393 & 1 (Ref.) & 1 (Ref.) & 995 & 1 (Ref.) & 1 (Ref.) \\
\hline & 1 & 427 & $0.73(0.64-0.83)$ & $0.74(0.65-0.84)$ & 335 & $0.89(0.76-1.03)$ & $0.90(0.77-1.05)$ & 762 & $0.79(0.72-0.87)$ & $0.80(0.73-0.88)$ \\
\hline \multirow[t]{2}{*}{ Physical activity } & 0 & 515 & 1 (Ref.) & 1 (Ref.) & 360 & 1 (Ref.) & 1 (Ref.) & 875 & 1 (Ref.) & 1 (Ref.) \\
\hline & 1 & 514 & $0.90(0.79-1.00)$ & $0.91(0.80-1.03)$ & 368 & $0.92(0.79-1.08)$ & $0.93(0.80-1.09)$ & 882 & $1.09(0.99-1.20)$ & $1.08(0.98-1.19)$ \\
\hline \multirow[t]{2}{*}{ Smoking } & 0 & 289 & 1 (Ref.) & 1 (Ref.) & 223 & 1 (Ref.) & 1 (Ref.) & 512 & 1 (Ref.) & 1 (Ref.) \\
\hline & 1 & 740 & $0.95(0.82-1.09)$ & $0.96(0.83-1.10)$ & 505 & $0.88(0.75-1.04)$ & $0.92(0.78-1.08)$ & 1,245 & $0.92(0.83-1.02)$ & $0.94(0.97-1.00)$ \\
\hline \multirow[t]{2}{*}{ Alcohol consumption } & 0 & 377 & 1 (Ref.) & 1 (Ref.) & 287 & 1 (Ref.) & 1 (Ref.) & 664 & 1 (Ref.) & 1 (Ref.) \\
\hline & 1 & 652 & $0.83(0.73 .0 .95)$ & $0.85(0.74-0.97)$ & 441 & $0.74(0.63-0.87)$ & $0.76(0.64-0.89)$ & 1,093 & $0.79(0.72-0.88)$ & $0.81(0.73-0.89)$ \\
\hline \multirow[t]{2}{*}{ Diet quality } & 0 & 451 & 1 (Ref.) & 1 (Ref.) & 342 & 1 (Ref.) & 1 (Ref.) & 793 & 1 (Ref.) & 1 (Ref.) \\
\hline & 1 & 578 & $0.88(0.76-1.00)$ & $0.89(0.78-1.02)$ & 386 & $0.78(0.67-0.92)$ & $0.80(0.68-0.94)$ & 964 & $0.84(0.75-0.93)$ & $0.85(0.77-0.95)$ \\
\hline \multicolumn{11}{|l|}{ Women } \\
\hline \multirow[t]{2}{*}{ Overweight and obesity } & 0 & 629 & 1 (Ref.) & 1 (Ref.) & 278 & 1 (Ref.) & 1 (Ref.) & 907 & 1 (Ref.) & 1 (Ref.) \\
\hline & 1 & 711 & $0.85(0.76-0.96)$ & $0.86(0.77-0.96)$ & 384 & $0.97(0.82-1.14)$ & $0.95(0.81-1.12)$ & 1,095 & $0.89(0.81-0.98)$ & $0.8980 .81-0.97)$ \\
\hline \multirow[t]{2}{*}{ Physical activity } & 0 & 629 & 1 (Ref.) & 1 (Ref.) & 288 & 1 (Ref.) & 1 (Ref.) & 917 & 1 (Ref.) & 1 (Ref.) \\
\hline & 1 & 711 & $0.85(0.75-0.95)$ & $0.86(0.77-0.97)$ & 374 & $1.16(0.98-1.37)$ & $1.17(0.99-1.38)$ & 1,085 & $0.94(0.85-1.04)$ & $0.95(0.86-1.05)$ \\
\hline \multirow[t]{2}{*}{ Smoking } & 0 & 261 & 1 (Ref.) & 1 (Ref.) & 155 & 1 (Ref.) & 1 (Ref.) & 416 & 1 (Ref.) & 1 (Ref.) \\
\hline & 1 & 1,079 & $0.87(0.76-1.01)$ & $0.88(0.77-1.02)$ & 507 & $0.76(0.63-0.92)$ & $0.76(0.63-0.93)$ & 1,586 & $0.83(0.74-0.93)$ & $0.84(0.75-0.94)$ \\
\hline
\end{tabular}


Table 3 Hazard ratios of colorectal cancer in relation to individual lifestyle factors, the EPIC cohort (1992 to 2010) (Continued)

\begin{tabular}{|c|c|c|c|c|c|c|c|c|c|c|}
\hline \multirow[t]{2}{*}{ Alcohol consumption } & 0 & 318 & 1 (Ref.) & 1 (Ref.) & 175 & 1 (Ref.) & 1 (Ref.) & 493 & 1 (Ref.) & 1 (Ref.) \\
\hline & 1 & 1,022 & $0.99(0.87-1.13)$ & $0.99(0.88-1.14)$ & 487 & $0.90(0.75-1.07)$ & $0.91(0.76-1.09)$ & 1,509 & $0.96(0.87-1.06)$ & $0.96(0.87-1.07)$ \\
\hline \multirow[t]{2}{*}{ Diet quality } & 0 & 633 & 1 (Ref.) & 1 (Ref.) & 287 & 1 (Ref.) & 1 (Ref.) & 920 & 1 (Ref.) & 1 (Ref.) \\
\hline & 1 & 707 & $0.84(0.75-0.95)$ & $0.86(0.77-0.97)$ & 375 & $0.98(0.83-1.17)$ & $1.00(0.84-1.18)$ & 1,082 & $0.89(0.81-0.98)$ & $0.91(0.82-1.00)$ \\
\hline
\end{tabular}

${ }^{a}$ Base model stratified by EPIC study centre and adjusted for age, sex, education (none, primary school, technical/professional school). ${ }^{b}$ Multivariable model stratified by EPIC study centre and adjusted for age, sex, education (none, primary school, technical/professional school, university degree) and after mutual adjustment for other lifestyle factors, including overweight and obesity, physical activity, smoking, alcohol

consumption, and diet quality (binary variables). Cl, confidence interval; EPIC, European Prospective Investigation into Cancer and Nutrition; HR, hazard ratio; PAR, population attributable fraction; Ref., reference. 


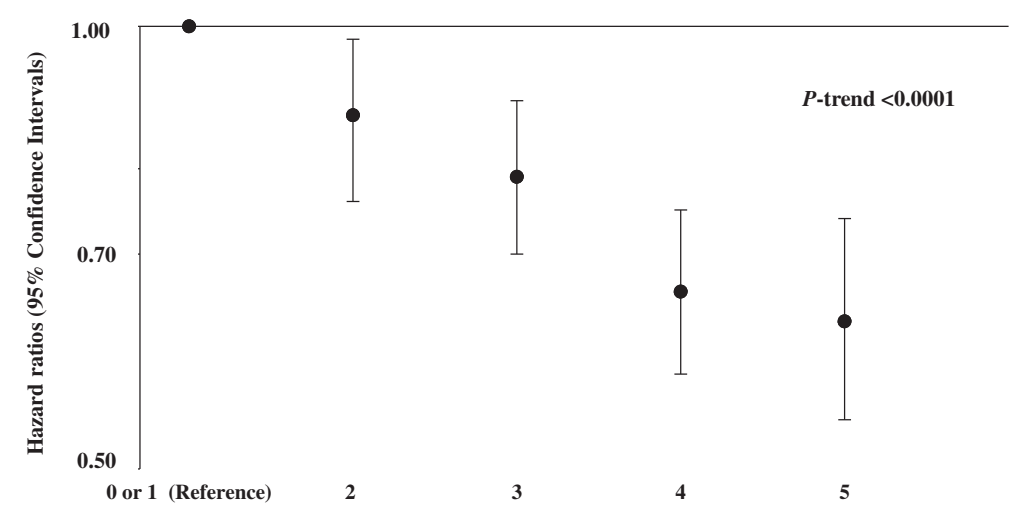

Figure 1 Multivariable-adjusted hazard ratios (95\% confidence intervals) of colorectal cancer according to increasing number of healthy lifestyle factors. Healthy lifestyle index (range 0 to 5 points) is calculated by summing the binary lifestyle factor variables $(0,1)$ including overweight and obesity, physical activity, smoking, alcohol consumption and diet quality. Participants received 1 point if they had any of the following behaviours: healthy weight, physically active, non-smokers or former smokers, limited alcohol consumption or healthy diet quality. The hazard ratios are calculated after stratification by EPIC study centre and multivariable adjustment for age at study recruitment, sex and educational status (none, primary school, technical/professional school/not specified). P-value for the linear trend was calculated using the Wald test treating the index as a continuous variable. EPIC. European Prospective Investigation into Cancer and Nutrition.

factors; whereas the risk of CRC was lower for several combinations of three healthy lifestyle factors (Figure 2). Among these, the combination of healthy weight, nonsmoking and a healthy diet ( $\mathrm{HR}=0.62$; $95 \% \mathrm{CI}: 0.49$ to 0.78 ) was associated with as lower risk as the combination of five lifestyle factors ( $H R=0.63$; $95 \%$ CI: 0.54 to 0.74 ). For most combinations, HLI scores of four and five were similarly protective. In stratified analyses, no substantial differences in the results were seen according to the age strata of less or more than 52.4 years $(P$-difference $=0.49)$ and by EPIC participating country [see Additional file 4: Figure S1; $P$-difference $=0.17]$. Overall there have not been major differences between participants with and without missing data according to the main study characteristics and exposure variables (data not shown). In sensitivity analyses, in a multivariable-adjusted model including age, sex and education, additional adjustment for family history did not substantially alter the risk estimate for the association between HLI and CRC: HR $=0.88$ (95\%CI: 0.86 to 0.91$) ; P$-value $<0.0001$. The results were also not markedly changed after excluding cases diagnosed with CRC within the first two years of study follow-up; the HR for one point increase on the index was 0.77 (95\% CI: 0.71 to 0.83 ).

In this large prospective cohort study over a median follow-up time of 12 years, an index based on five potentially modifiable healthy lifestyle factors including healthy weight, physical activity, non-smoking, limited alcohol consumption and a healthy diet was inversely associated with CRC risk. The associations were stronger among men compared to women, particularly for rectal cancer. If these associations were causal, $16 \%$ of the new CRC cases (22\% in men and $11 \%$ in women) would have been prevented had all participants been following all five healthy lifestyles. These findings provide sex and cancer-site specific estimates of the public health burden of combined lifestyle factors for incident CRC in these European populations.

Given the high incidence and mortality rates [37], prevention strategies for reducing CRC are highly desired. In this context, there have been numerous studies exploring individual lifestyle factors with regard to CRC risk $[11,38-40]$. However, studies on the combined effect of lifestyle factors on CRC risk have been more sparse [41-43]. In a study of 47,927 US men in the prospective Health Professionals Follow-up Cohort, after adjusting for age and family history of CRC comparing the risk score for the combined six modifiable colon cancer risk factors (obesity, physical inactivity, alcohol consumption, early adulthood cigarette smoking, red meat consumption and low intake of folic acid from supplements) at or above the approximate 20th, 10th, or 5th percentiles versus below, the PAR\% increased from 39\% to $48 \%$ and 55\%, respectively [41]. In the Nurses' Health Study among 83,767 US women, those who smoked, had a consistently high relative weight, low physical activity level, consumed red or processed meat on a daily basis, were never screened, and consumed low daily amounts of folate had almost a four-fold higher risk of colon cancer by the age of 70 years [43]. Another two studies provided data for European populations. A Danish Diet Cancer and Health cohort study [42] among 55,487 men and women, reported $11 \%$ lower risk of CRC in people who adhered to five healthy lifestyle recommendations, including high physical activity, low waist circumference, not smoking, low alcohol intake and a healthy diet (dietary fibre, energy percentage from fat, red and processed meat, and fruits and vegetables). However, the study included participants 
Table 4 Hazard ratios (HRs) of colorectal cancer according to the Healthy Lifestyle Index (HLI) ${ }^{\mathrm{a}}$, the EPIC cohort (1992 to 2010)

\begin{tabular}{|c|c|c|c|c|c|c|}
\hline \multirow[t]{2}{*}{$\mathrm{HLI}$} & \multicolumn{2}{|l|}{ Colon cancer } & \multicolumn{2}{|l|}{ Rectal cancer } & \multicolumn{2}{|c|}{ Colorectal cancer } \\
\hline & Cases, number & $\mathrm{HR}^{\mathrm{b}}(95 \% \mathrm{Cl})$ & Cases, number & $\mathrm{HR}^{\mathrm{b}}(95 \% \mathrm{Cl})$ & Cases, number & $\mathrm{HR}^{\mathrm{b}}(95 \% \mathrm{Cl})$ \\
\hline \multicolumn{7}{|l|}{ All participants } \\
\hline 0 or 1 & 216 & 1 (Reference) & 133 & 1 (Reference) & 349 & 1 (Reference) \\
\hline 2 & 526 & 0.85 (0.72 to 0.99$)$ & 326 & $0.90(0.74$ to 1.11$)$ & 852 & 0.87 (0.76 to 0.98$)$ \\
\hline 3 & 816 & 0.78 (0.67 to 0.91) & 459 & 0.80 (0.66 to 0.97$)$ & 1275 & 0.79 (0.70 to 0.89$)$ \\
\hline 4 & 602 & 0.64 (0.54 to 0.75) & 348 & 0.70 (0.57 to 0.85$)$ & 950 & 0.66 (0.58 to 0.75$)$ \\
\hline 5 & 209 & 0.61 (0.50 to 0.74) & 124 & 0.68 (0.53 to 0.88$)$ & 333 & 0.63 (0.54 to 0.74$)$ \\
\hline$P$-trend & & $<0.0001$ & & $<0.0001$ & & $<0.0001$ \\
\hline Per one point increase & & 0.87 (0.84 to 0.91) & & 0.90 (0.85 to 0.94$)$ & & 0.88 (0.86 to 0.92$)$ \\
\hline$P$-value ${ }^{c}$ & & $<0.0001$ & & $<0.0001$ & & $<0.0001$ \\
\hline \multicolumn{7}{|l|}{ Men } \\
\hline 0 or 1 & 135 & 1 (Reference) & 94 & 1 (Reference) & 229 & 1 (Reference) \\
\hline 2 & 266 & 0.80 (0.65 to 0.98$)$ & 196 & 0.87 (0.67 to 1.10$)$ & 462 & 0.83 (0.71 to 0.97$)$ \\
\hline 3 & 330 & 0.70 (0.57 to 0.85$)$ & 236 & 0.75 (0.59 to 0.95$)$ & 566 & 0.72 (0.62 to 0.84$)$ \\
\hline 4 & 215 & 0.59 (0.46 to 0.73$)$ & 160 & 0.66 (0.51 to 0.85$)$ & 375 & 0.62 (0.52 to 0.73$)$ \\
\hline 5 & 83 & 0.61 (0.46 to 0.81$)$ & 42 & 0.47 (0.32 to 0.68$)$ & 125 & 0.56 (0.44 to 0.69$)$ \\
\hline$P$-trend & & $<0.0001$ & & $<0.0001$ & & $<0.0001$ \\
\hline Per one point increase & & 0.86 (0.82 to 0.91$)$ & & 0.86 (0.80 to 0.91$)$ & & 0.87 (0.83 to 0.90$)$ \\
\hline$P$-value ${ }^{c}$ & & $<0.0001$ & & $<0.0001$ & & $<0.0001$ \\
\hline \multicolumn{7}{|l|}{ Women } \\
\hline 0 or 1 & 81 & 1 (Reference) & 39 & 1 (Reference) & 120 & 1 (Reference) \\
\hline 2 & 260 & 0.93 (0.73 to 1.20) & 130 & 1.03 (0.72 to 1.48$)$ & 390 & 0.97 (0.78 to 1.18$)$ \\
\hline 3 & 486 & 0.91 (0.71 to 1.14) & 223 & 0.96 (0.68 to 1.36$)$ & 709 & 0.92 (0.76 to 1.12$)$ \\
\hline 4 & 387 & 0.72 (0.56 to 0.92) & 188 & 0.84 (0.59 to 1.19) & 575 & 0.76 (0.62 to 0.93$)$ \\
\hline 5 & 126 & 0.65 (0.48 to 0.86$)$ & 82 & 1.01 (0.68 to 1.49 ) & 208 & 0.76 (0.60 to 0.95$)$ \\
\hline$P$-trend ${ }^{c}$ & & $<0.0001$ & & 0.35 & & $<0.0001$ \\
\hline Per one point increase & & 0.88 (0.84 to 0.93$)$ & & 0.97 (0.99 to 1.04) & & 0.91 (0.87 to 0.95$)$ \\
\hline$P$-value & & $<0.0001$ & & 0.35 & & $<0.0001$ \\
\hline
\end{tabular}

${ }^{a}$ Healthy lifestyle index (range 0 to 5 points) is calculated by summing the binary lifestyle factor variables $(0,1)$ including overweight and obesity, physical activity, smoking, alcohol consumption and diet quality. Participants received one point if they had any of the following behaviours: healthy weight, physically active, non-smokers or former smokers, limited alcohol consumption or healthy diet quality. ${ }^{b}$ Multivariable model stratified by EPIC study centre and adjusted for age at study recruitment, sex and educational status (none, primary school, technical/professional school/not specified). ${ }^{c} P$-value for the linear trend was calculated using the Wald test treating the index as a continuous variable. Note: $P$-interaction by sex: 0.40 , for colon cancer; 0.008 for rectal cancer; 0.03 for colorectal cancer. $P$ for interaction is assessed using the likelihood ratio test by generating a cross-product term between $\mathrm{HLI}$ and sex in the multivariable model. $\mathrm{Cl}$, confidence interval; EPIC, European Prospective Investigation into Cancer and Health; HR, hazard ratio.

only from Denmark and, therefore, its results may not be generalisable for other European populations. Using data from the EPIC cohort [44], a one-point increment in an index based on the 2007 WCRF/AICR recommendations was associated with a risk reduction of $12 \%$ (95\% CI: $9 \%$ to $16 \%)$ for CRC. However, this index was based solely on BMI to define body fatness, whereas waist circumference as a measure of abdominal obesity has been suggested to be a more specific indicator for elevated metabolic risk [45]. In particular, visceral adipose tissue is physiologically more active than subcutaneous adipose tissue and generates hormones and cytokines with inflammatory, metabolic and direct carcinogenic potential, which may directly or indirectly promote cancer development. Suggested putative mechanisms that may account for the link between obesity and CRC risk include hyperinsulinaemia, chronic low-grade inflammation, altered immune response, oxidative stress, as well as disturbances in insulinlike growth factors, adipokines and sex steroids. In addition, evidence has shown that while BMI is associated with CRC risk in men only, abdominal obesity (as determined by waist circumference) is similarly strongly associated with CRC cancer both in men and in women, suggesting that it may reflect cancer risk in both sexes 
Table 5 Population attributable risks (PARs) according to individual lifestyle factors and combined Healthy Lifestyle Index (HLI) ${ }^{\text {, }}$, the EPIC Cohort (1992 to 2010)

\begin{tabular}{|c|c|c|c|c|c|c|}
\hline & \multicolumn{2}{|l|}{ Colon cancer } & \multicolumn{2}{|l|}{ Rectal cancer } & \multicolumn{2}{|l|}{ Colorectal cancer } \\
\hline & Cases, number ${ }^{\mathbf{b}}$ & \%PAR (95\% Cl) & Cases, number ${ }^{b}$ & \%PAR $(95 \% \mathrm{Cl})$ & Cases, number ${ }^{\mathbf{b}}$ & \%PAR $(95 \% \mathrm{Cl})$ \\
\hline \multicolumn{7}{|l|}{ All participants } \\
\hline \multicolumn{7}{|l|}{ Individual lifestyle factors ${ }^{\mathrm{c}}$ : } \\
\hline Overweight and obesity & 1,231 & $10(6$ to 13$)$ & 671 & $3(-1$ to 7$)$ & 1,902 & $8(5$ to 11$)$ \\
\hline Physical activity & 1,144 & $6(2$ to 10$)$ & 648 & NA & 1,792 & $3(0$ to 6$)$ \\
\hline Smoking & 550 & $2(-3$ to 4$)$ & 378 & $4(1$ to 7$)$ & 928 & $4(1$ to 6$)$ \\
\hline Alcohol consumption & 695 & $2(-1$ to 4$)$ & 462 & $6(2$ to 9$)$ & 1,157 & $4(1$ to 6$)$ \\
\hline Diet quality & 1,084 & 5 (2 to 8$)$ & 629 & $5(-2$ to 9$)$ & 1,713 & 5 (2 to 7$)$ \\
\hline$H L I<5^{d}$ & 2,160 & 17 (6 to 26$)$ & 1,266 & 13 ( -4 to 27$)$ & 3,426 & 16 (7 to 24) \\
\hline \multicolumn{7}{|l|}{ Men } \\
\hline \multicolumn{7}{|l|}{ Individual lifestyle factors ${ }^{c}$ : } \\
\hline Overweight and obesity & 602 & 15 (8 to 21$)$ & 393 & $5(-2$ to 11$)$ & 995 & $10(5$ to 14$)$ \\
\hline Physical activity & 515 & $4(-2$ to 9$)$ & 360 & $5(-7$ to 15$)$ & 875 & $3(-1$ to 6$)$ \\
\hline Smoking & 289 & $1(-2$ to 4$)$ & 223 & $3(-2$ to 8$)$ & 512 & $4(-3$ to 11$)$ \\
\hline Alcohol consumption & 377 & $5(1$ to 9$)$ & 287 & $12(5$ to 18$)$ & 664 & 7 (3 to 10$)$ \\
\hline Diet quality & 451 & $4(-1$ to 9$)$ & 342 & 12 (3 to 20$)$ & 793 & $6(1$ to 10$)$ \\
\hline$H L I<5^{d}$ & 946 & $13(-8$ to 28$)$ & 686 & 36 (13 to 53$)$ & 1,632 & 22 (7 to 34) \\
\hline \multicolumn{7}{|l|}{ Women } \\
\hline \multicolumn{7}{|l|}{ Individual lifestyle factors ${ }^{c}$ : } \\
\hline Overweight and obesity & 629 & $7(2$ to 11$)$ & 278 & $2(-5$ to 8$)$ & 907 & 5 (1 to 9$)$ \\
\hline Physical activity & 629 & 7 (1 to 12$)$ & 288 & NA & 917 & $2(-2$ to 6$)$ \\
\hline Smoking & 261 & $11(-27$ to 37$)$ & 155 & $2(-2$ to 6$)$ & 416 & 1 ( -1 to 2$)$ \\
\hline Alcohol consumption & 318 & NA & 175 & $2(-2$ to 6$)$ & 493 & $1(-3$ to 4$)$ \\
\hline Diet quality & 633 & 6 (1 to 10$)$ & 287 & NA & 920 & $2(0$ to 4$)$ \\
\hline$H L I<5^{\mathrm{d}}$ & 1,214 & 20 (6 to 32$)$ & 580 & $N A$ & 1,794 & 11 (1 to 21) \\
\hline
\end{tabular}

${ }^{a}$ The $\mathrm{HLI}$ (range 0 to 5 points) is calculated by summing the binary lifestyle factor variables $(0,1)$ including overweight and obesity, physical activity, smoking, alcohol consumption and diet quality. Participants received one point if they had any of the following behaviours: healthy weight, physically active, non-smokers or former smokers, limited alcohol consumption or healthy diet quality. ${ }^{\text {b}}$ The number of cases denotes those cases without the healthy lifestyle factor or not adhering to all five healthy lifestyle factors. 'PAR according to each of the individual lifestyle factors, stratified by EPIC study centre, and adjusted for age, sex, education (none, primary school, technical/professional school) and mutually adjusted for the other lifestyle factors, including overweight and obesity, physical activity, smoking, alcohol consumption and diet quality (binary variables). PARs are calculated by reversing the coding of the protective factors and taking into account the relative proportion of exposed cases based on the formula from Miettinen et al. [31]. The 95\% Cls are calculated based on the formula of Whittemore et al. [33]. The PARs denote the percentage of colorectal cancer cases in the population that are attributable to the non-adherence to the particular healthy

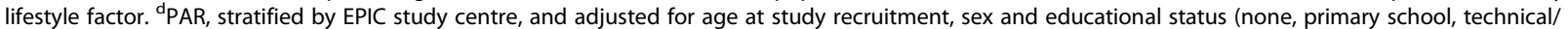
professional school). The PAR denotes the percentage of colorectal cancer cases in the population that are attributable to the non-adherence to five healthy lifestyle behaviours. PARs are calculated based on a formula from Bruzzi et al. [32]. The $95 \%$ Cls are calculated based on the formula of Whittemore et al. [33]. Note: No meaningful PAR estimates were obtained for the associations of : physical activity and rectal cancer in all participants; alcohol consumption and colon cancer in women; as well as for physical activity and diet quality and rectal cancer in women, because the estimated hazard ratios for these individual factors in women were close to 1 (Please, see Table 3). Cl, confidence interval; EPIC, European Prospective Investigation into Cancer and Nutrition.

more adequately compared to BMI [18]. Indeed, in our data when only BMI was used to define healthy weight, the estimated HR of CRC was 0.93 (95\% CI: 0.87 to 1.00), whereas the respective risk estimate for using only waist circumference was lower: $\mathrm{HR}=0.82$ (95\% CI: 0.78 to 0.87). Taking the above into consideration, in our study we used both BMI and waist circumference to define healthy weight. Furthermore, the WCRF /AICR score used general dietary recommendations for cancer prevention, whereas it may be important to consider foods that have been specifically related to CRC risk. We designed an $a$ - priori based healthy diet quality index that comprised individual foods specifically shown to be associated to CRC risk [2-8,11,12,38-40]. Using this index, we observed $37 \%$ lower risk of CRC for people having all five healthy lifestyle factors relative to those with none of these healthy factors.

In the present study we observed a stronger association between HLI and CRC among men than among women. Similar findings have been reported also by the Danish Diet Cancer and Health study [42], although the number of cases was much lower in that study and the 


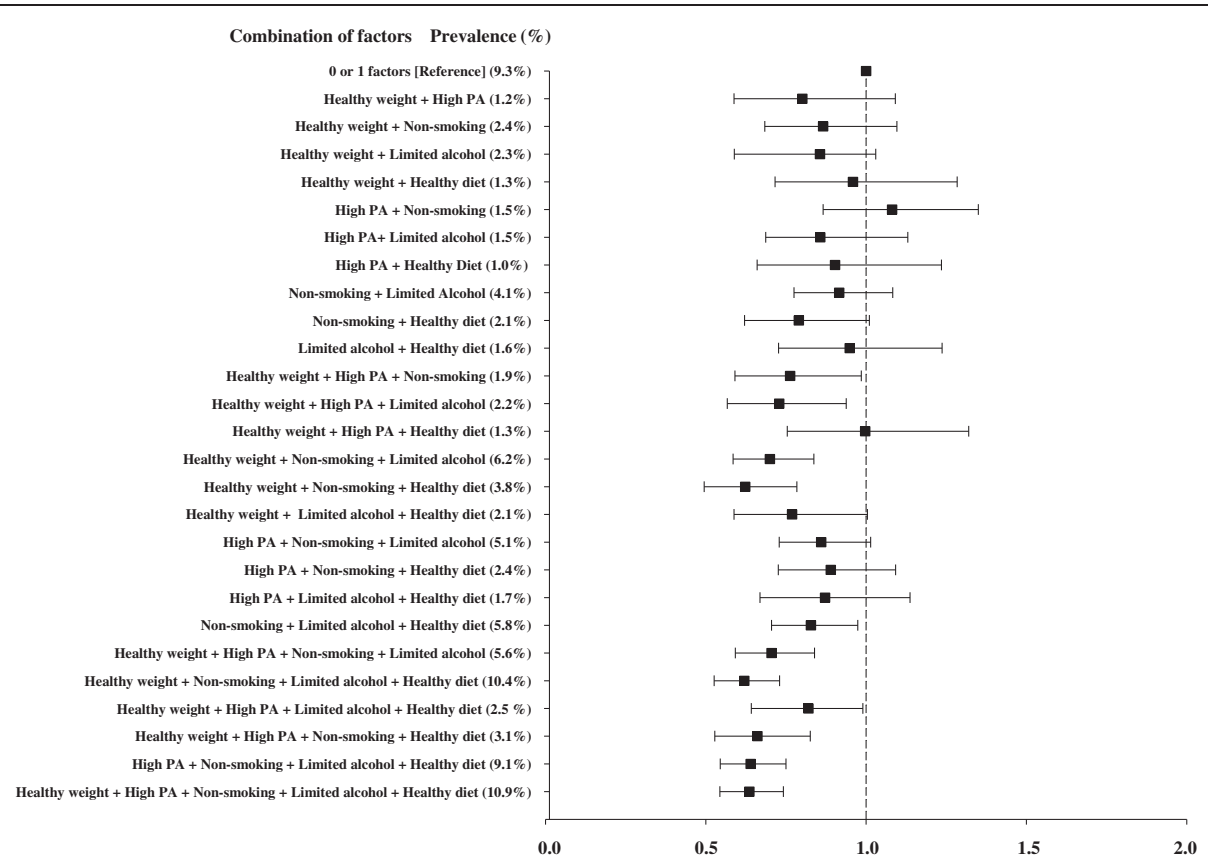

Figure 2 Multivariable-adjusted hazard ratios of colorectal cancer according to combinations of healthy lifestyle factors. HRs are shown for persons with the respective combination of healthy lifestyle factors compared with persons with none or one of the lifestyle factors; The multivariable model is stratified by EPIC study centre and adjusted for age at study recruitment, sex and educational status (none, primary school, technical/professional school/ not specified). The presented prevalences (\%) represent the frequency distribution of the respective combinations of healthy lifestyle factors among the total study population. Within the reference group of individuals with 0 or 1 healthy lifestyle factors, $0.8 \%$ had 0 factors, $1.1 \%$ had only healthy weight; $0.85 \%$ had only high physical activity, $1.6 \%$ had only non-smoking, $1.4 \%$ had only limited alcohol and $0.9 \%$ had only healthy diet. Cl, confidence interval; EPIC, European Prospective Investigation into Cancer and Nutrition; HR, hazard ratio.

interaction by sex was not statistically significant. In addition, we also observed a cancer site and sex-specific gradient in the PARs such that $36 \%$ of rectal cancer cases in men and $20 \%$ of colon cancer cases in women would have been prevented if all participants adhered to all five healthy lifestyle factors, whereas no statistically significant PARs were seen in men for colon cancer and in women for rectal cancer. These suggested sex differences could be accounted for by differences in exposure distribution among men and women, quality of reporting lifestyle data or by biological differences among sexes. Our data revealed that overweight and obesity statistically explained the association between HLI and colon cancer in men but not in women. These data are in line with previous evidence on the role of obesity as a stronger risk factor for colon cancer in men compared to women [18]. Different biological mechanisms have been suggested to explain the associations of obesity and colon cancer in men and in women. Thus, our previous work has suggested that inflammation and oxidative stress underlies this association in men, whereas hyperinsulinaemia was the candidate explaining the pathway in women [46]. More research is needed to shed light on potential biological pathways that may underlie these relations.

When interpreting PARs, it should be taken into account that these measures rely on the distribution of lifestyle factors among participants in the present cohort study. Furthermore, PARs assume that the exposures are causal and unbiased, but studies with observational design are not sufficiently able to prove this assumption. Nevertheless, this knowledge may still be useful for tailoring interventions for lifestyle modification at target population subgroups.

As lifestyle patterns occur simultaneously and the magnitude of the associations may vary according to each individual's present factors, we also examined the associations according to different combinations of factors. In these analyses, we observed that a combination of three factors, including healthy weight, non-smoking and a healthy diet quality, was related to a lower CRC risk as low as the five factors altogether, suggesting the relative importance of this particular healthy lifestyle pattern for CRC prevention. However, due to the low prevalence of each specific combination of factors, more research is needed to investigate diversity of lifestyle patterns in relation to CRC risk.

The strengths of the present study include the large sample size, the prospective study design, and the long follow-up time of the EPIC cohort. An important advantage of the study is the availability of measured rather than self-reported anthropometric information, as well as detailed dietary and lifestyle information collected using 
standardised procedures and validated instruments. The present study has several limitations. In order to construct the HLI, we dichotomised each lifestyle factor according to pre-defined cut-off points. Different threshold values would have resulted in different risk estimates. The choice of cut-off points was mostly based on public health recommendations and was generalised rather than riskspecific. Because the use of equal weights is an imperfect approximation of the underlying biological relationships between the different health behaviours and CRC, future analyses should examine the potential influence of the different weightings. The dichotomisation of variables included in the lifestyle index is associated with several methodological challenges, including loss of information, power and potential for underestimating the extent of variation in risk. Discarding a high proportion of the data is particularly problematic when studies are too small and, hence, underpowered. However, EPIC is a large prospective study with a long follow-up time, therefore having sufficient power to detect underlying relationships between healthy lifestyle factors and CRC risk. Nevertheless, the likely influence of the dichotomisation of the variables in the index is underestimating the true effect of the observed associations. We used multivariable models to adjust for additional confounders; however, the potential for residual confounding remains. Measurement error in selfreported variables cannot be ruled out; however, such error would likely lead to a non-differential bias potentially leading to underestimating the true effects. We used a simplified diet quality index that may not sufficiently account for the complexity of diets. A large proportion of participants were excluded because of missing information on main exposure variables which may have potentially biased the risk estimates if the participants with missing data are not similar to those with complete data. In our data overall there have not been major differences between participants with and without missing data according to the main study characteristics and exposure variables; therefore, it is unlikely that using the complete data analysis approach would have influenced our findings. Endoscopic examinations of the large bowel have been associated with general health behaviour and lower $\mathrm{CRC}$ risk and, therefore, may potentially confound the association between lifestyle factors and CRC risk. Unfortunately, in the EPIC study no information on CRC screening, that is, colonoscopy or sigmoidoscopy, has been systematically collected and we were not able to account for this factor in statistical analyses. However, previous studies which controlled for colonoscopy screening did not report a change in the association between healthy lifestyle behaviours and CRC risk [47]. In addition, when we stratified the analyses by age of 50 or 55 when most screening programs in Europe are introduced, we did not observe different results; therefore, it is unlikely that the main study findings could have been largely influenced by this factor. Finally, the combined HLI did not include all possible lifestyles, that is, non-steroidal anti-inflammatory drug use or dietary nutrients (calcium, vitamin D) that could additionally influence CRC risk. If added to the index, the estimated PARs could have been potentially higher.

\section{Conclusions}

In conclusion, combined lifestyle factors - healthy weight, high physical activity, non-smoking, limited alcohol consumption and a healthy diet - are associated with a lower CRC incidence in European populations characterized by western lifestyles. These data support the notion that the complex nature and multiple dimensions of health behaviours may be better captured in analyses of lifestyle factors in combination compared to modeling individual factors alone. From a prevention perspective, using combinations of modifiable lifestyle factors in CRC risk assessment promises to be a successful, yet simple, approach for translation of epidemiologic findings into primary cancer prevention.

\section{Additional files}

Additional file 1: Table S1. Ethical approval review board information for local EPIC centres.

Additional file 2: Table S2. Composition of the Diet Quality Index.

Additional file 3: Table S3. Percent Change in Regression Coefficients for Colorectal Cancer Associated with the Healthy Lifestyle Index (continuously) with Adjustment for each Healthy Lifestyle Factor, the EPIC cohort (1992-2010).

Additional file 4: Figure S1. Multivariable-adjusted Hazard Ratios of the Association between $\mathrm{HLI}$ and Colorectal Cancer across EPIC participating countries.

\section{Abbreviations}

BMI: body mass index; Cl: confidence interval; CRC: colorectal cancer; EPIC: European Prospective Investigation into Cancer and Nutrition; HLI: Healthy Lifestyle Index; HR: hazard ratio; PAR: population attributable risk; WCRF/AICR: World Cancer Research Fund/American Institute for Cancer Research.

\section{Competing interests}

The authors declare that they have no competing interests.

\section{Authors' contributions}

KA had full access to all of the data in the study and takes responsibility for the integrity of the data and the accuracy of the data analysis. Study concept and design: KA and HB. Analysis and interpretation of data: KA, TP, MJ, HBBDM, TN, DR, VF, SK, HB. Drafting of the manuscript: KA. Critical revision of the manuscript for important intellectual content: $M-C B-R, L D$, LD, RK, KL, AT, KO, JEQ, GB, MJS, MD, M-D C, AB, K-T K, NJW, KEB, AT, PL, DT, DP, VK, RT, AN, SP, PDS, PHMP, IL, IJ, UE, BO, EW, GS, KBB, SR, IR, JK, MJG, HAW, ER. Administrative, technical, and material support: HB. Study supervision: HB. All authors read and approved the final manuscript.

\section{Acknowledgements}

The authors thank Ellen Kohlsdorf (German Institute of Human Nutrition Potsdam-Rehbrücke, Nuthetal, Germany ) for her work on data management 
and technical assistance. The authors thank all participants in the EPIC study for their outstanding cooperation.

\section{Funding/Support}

The coordination of the EPIC study is financially supported by the European Commission (DG-SANCO) and the International Agency for Research on Cancer. The national cohorts are supported by Danish Cancer Society (Denmark); Ligue Contre le Cancer, Institut Gustave Roussy, Mutuelle Générale de l'Education Nationale, Institut National de la Santé et de la Recherche Médicale (INSERM) (France); Deutsche Krebshilfe, Deutsches Krebsforschungszentrum and Federal Ministry of Education and Research (Germany); Hellenic Health Foundation (Greece); Italian Association for Research on Cancer (AIRC), National Research Council, HuGeF Foundation, Compagnia di San Paolo, Sicily Regional Government, AIRE ONLUS Ragusa and AVIS Ragusa (Italy); Dutch Ministry of Public Health, Welfare and Sports (WWS), Netherlands Cancer Registry (NKR), LK Research Funds, Dutch Prevention Funds, Dutch ZON (Zorg Onderzoek Nederland), World Cancer Research Fund (WCRF) and Statistics Netherlands (The Netherlands); ERC2009-AdG 232997 and Nordforsk, Nordic Centre of Excellence programme on Food, Nutrition and Health, Norwegian Research Council, Norwegian Cancer Society, University of Tromso (Norway); Health Research Fund (FIS), Regional Governments of Andalucía, Asturias, Basque Country, Murcia (no. 6236) and Navarra, ISCIII RETIC (RD06/0020) (Spain); Swedish Cancer Society, Swedish Scientific Council and Regional Government of Skåne and Västerbotten (Sweden); Cancer Research UK, Medical Research Council (United Kingdom). Role of the Sponsors: The funders had no role in the design and conduct of the study; collection, management, analysis and interpretation of the data; or preparation, review or approval of the manuscript.

\section{Author details}

'Department of Epidemiology, German Institute of Human Nutrition Potsdam-Rehbrücke, Nuthetal, Germany. ${ }^{2}$ Molecular Epidemiology Group, Max Delbrueck Center for Molecular Medicine (MDC), Berlin-Buch, Germany. ${ }^{3}$ International Agency for Research on Cancer (IARC-WHO), Lyon, France. ${ }^{4}$ National Institute for Public Health and the Environment (RIVM), Bilthoven, Netherlands. ${ }^{5}$ Department of Gastroenterology and Hepatology, University Medical Center, Utrecht, the Netherlands. ${ }^{6}$ Department of Epidemiology and Biostatistics, School of Public Health, Imperial College London, London, UK. ${ }^{7}$ Department of Epidemiology, Rollins School of Public Health, Winship Cancer Institute, Emory University, Atlanta, GA, USA. ${ }^{8}$ Instituto de Investigacion Sanitaria de Palma (IdISPa), Hospital Universitario Son Espases, Palma de Mallorca, Spain. ${ }^{9} \mathrm{CIBER}$ Fisiopatología de la Obesidad y Nutrición (CIBEROBN), Santiago de Compostela, Spain. ${ }^{10}$ Inserm, Centre for research in Epidemiology and Population Health (CESP), U1018, Nutrition, Hormones and Women's Health team, F-94805 Villejuif, France. ${ }^{11}$ Univ Paris Sud, UMRS 1018, F-94805 Villejuif, France. ${ }^{12}$ IGR, F-94805 Villejuif, France. ${ }^{13}$ Division of Cancer Epidemiology, German Cancer Research Centre, Heidelberg, Germany. ${ }^{14}$ Diet, Genes and Environment Danish Cancer Society Research Center, Copenhagen, Denmark. ${ }^{15}$ Department of Public Health, Section for Epidemiology, Aarhus University, Aarhus, Denmark. ${ }^{16}$ Public Health Directorate, Asturias, Spain. ${ }^{17}$ Unit of Nutrition, Environment and Cancer, Cancer Epidemiology Research Programme, Catalan Institute of Oncology (ICO-IDIBELL), Barcelona, Spain. ${ }^{18}$ Escuela Andaluza de Salud Pública. Instituto de Investigación Biosanitaria de Granada (Granada.ibs), Granada, Spain. ${ }^{19} \mathrm{CIBER}$ de Epidemiología y Salud Pública (CIBERESP), Madrid, Spain. ${ }^{20}$ Epidemiology and Health Information, Public Health Division of Gipuzkoa, Basque Regional Health Department, San Sebastian, Spain. ${ }^{21}$ Department of Epidemiology, Murcia Regional Health Authority, Murcia, Spain. ${ }^{22}$ Navarre Public Health Institute, Pamplona, Spain. ${ }^{23}$ Clinical Gerontology Unit, Addenbrooke's Hospital, University of Cambridge School of Clinical Medicine, Cambridge, UK. ${ }^{24} \mathrm{MRC}$ Epidemiology Unit, Institute of Metabolic Science, University of Cambridge School of Clinical Medicine, Cambridge, UK. ${ }^{25}$ Cancer Epidemiology Unit, Nuffield Department of Population Health, University of Oxford, Oxford, UK. ${ }^{26}$ Hellenic Health Foundation, Athens, Greece. ${ }^{27}$ Bureau of Epidemiologic Research, Academy of Athens, Athens, Greece. ${ }^{28}$ Department of Hygiene, Epidemiology and Medical Statistics, University of Athens Medical School, Athens, Greece. ${ }^{29}$ Department of Epidemiology, Harvard School of Public Health, Boston, MA, USA. ${ }^{30}$ Molecular and Nutritional Epidemiology Unit, Cancer Research and Prevention Institute - ISPO, Florence, Italy. ${ }^{31}$ Epidemiology and Prevention Unit, Fondazione IRCCS Istituto Nazionale dei Tumori, Milan, Italy. ${ }^{32}$ Cancer Registry and
Histopathology Unit, "M.P.Arezzo" Hospital, Ragusa, Italy. ${ }^{33} \mathrm{HuGeF}$ - Human Genetics Foundation - Torino, Molecular and Genetic Epidemiology Unit, Turin, Italy. ${ }^{34}$ Department of clinical and experimental medicine-Federico ॥ University, Naples, Italy. ${ }^{35}$ Department of Epidemiology, Julius Center for Health Sciences and Primary Care, University Medical Center, Utrecht, the Netherlands. ${ }^{36}$ Department of Radiation Sciences, Oncology, Umeå University, Umeå, Sweden. ${ }^{37}$ Department of Odontology, Umeå University, Umeå, Sweden. ${ }^{38}$ Diabetes and Cardiovascular Disease, Genetic Epidemiology, Department of Clinical Sciences in Malmö, Lund University, Malmö, Sweden. ${ }^{39}$ Department of Clinical Sciences, Division of Internal Medicine, Skåne University Hospital Malmö, Lund University, Malmö, Sweden. ${ }^{40}$ Department of Community Medicine, Faculty of Health Sciences, University of Tromso, The Arctic University of Norway, Troms $\varnothing$, Norway. ${ }^{41}$ Department of Research, Cancer Registry of Norway, Oslo, Norway. ${ }^{42}$ Department of Medical Epidemiology and Biostatistics, Karolinska Institutet, Stockholm, Sweden. ${ }^{43}$ Samfundet Folkhälsan, Helsinki, Finland.

Received: 27 June 2014 Accepted: 29 August 2014

Published online: 10 October 2014

\section{References}

1. Ferlay JS, Ervik M, Dikshit R, Eser S, Mathers C, Rebelo M, Parkin DM, Forman $D$, Bray F: Cancer incidence and mortality worldwide: IARC CancerBase. In GLOBOCAN 2012 v10, Volume 11. Lyon, France: International Agency for Research on Cancer; 2013.

2. Bingham S: The fibre-folate debate in colo-rectal cancer. Proc Nutr Soc 2006, 65:19-23.

3. Bingham SA, Day NE, Luben R, Ferrari P, Slimani N, Norat T, Clavel-Chapelon F, Kesse E, Nieters A, Boeing H, Tjønneland A, Overvad K, Martinez C, Dorronsoro M, Gonzalez CA, Key TJ, Trichopoulou A, Naska A, Vineis P, Tumino R, Krogh V, Bueno-de-Mesquita HB, Peeters PH, Berglund G, Hallmans G, Lund E, Skeie G, Kaaks R, Riboli E, European Prospective Investigation into Cancer and Nutrition: Dietary fibre in food and protection against colorectal cancer in the European Prospective Investigation into Cancer and Nutrition (EPIC): an observational study. Lancet 2003, 361:1496-1501.

4. Ferrari $P$, Jenab M, Norat T, Moskal A, Slimani N, Olsen A, Tjonneland A, Overvad K, Jensen MK, Boutron-Ruault MC, Clavel-Chapelon F, Morois S, Rohrmann S, Linseisen J, Boeing H, Bergmann M, Kontopoulou D, Trichopoulou A, Kassapa C, Masala G, Krogh V, Vineis P, Panico S, Tumino R, van Gils CH, Peeters P, Bueno-de-Mesquita HB, Ocké MC, Skeie G, Lund E, et al: Lifetime and baseline alcohol intake and risk of colon and rectal cancers in the European prospective investigation into cancer and nutrition (EPIC). Int J Cancer 2007, 121:2065-2072.

5. Jenab M, Ferrari P, Slimani N, Norat T, Casagrande C, Overad K, Olsen A, Stripp C, Tjonneland A, Boutron-Ruault MC, Clavel-Chapelon F, Kesse E, Nieters A, Bergmann M, Boeing H, Naska A, Trichopoulou A, Palli D, Krogh V, Celentano E, Tumino R, Sacerdote C, Bueno-de-Mesquita HB, Ocké MC, Peeters PH, Engeset D, Quirós JR, González CA, Martínez C, Chirlaque MD, et al: Association of nut and seed intake with colorectal cancer risk in the European Prospective Investigation into Cancer and Nutrition. Cancer Epidemiol Biomarkers Prev 2004, 13:1595-1603.

6. Norat T, Bingham S, Ferrari P, Slimani N, Jenab M, Mazuir M, Overvad K, Olsen A, Tjonneland A, Clavel F, Boutron-Ruault MC, Kesse E, Boeing H, Bergmann MM, Nieters A, Linseisen J, Trichopoulou A, Trichopoulos D, Tountas Y, Berrino F, Palli D, Panico S, Tumino R, Vineis P, Bueno-deMesquita HB, Peeters PH, Engeset D, Lund E, Skeie G, Ardanaz E, et al: Meat, fish, and colorectal cancer risk: the European Prospective Investigation into cancer and nutrition. J Nat/ Cancer Inst 2005, 97:906-916.

7. Pischon $\mathrm{T}$, Lahmann $\mathrm{PH}$, Boeing $\mathrm{H}$, Friedenreich $\mathrm{C}$, Norat $\mathrm{T}$, Tjonneland $\mathrm{A}$, Halkjaer J, Overvad K, Clavel-Chapelon F, Boutron-Ruault MC, Guernec G, Bergmann MM, Linseisen J, Becker N, Trichopoulou A, Trichopoulos D, Sieri S, Palli D, Tumino R, Vineis P, Panico S, Peeters PH, Bueno-de-Mesquita HB, Boshuizen HC, Van Guelpen B, Palmqvist R, Berglund G, Gonzalez CA, Dorronsoro M, Barricarte A, et al: Body size and risk of colon and rectal cancer in the European Prospective Investigation Into Cancer and Nutrition (EPIC). J Natl Cancer Inst 2006, 98:920-931.

8. van Duijnhoven FJ, Bueno-De-Mesquita HB, Ferrari P, Jenab M, Boshuizen HC, Ros MM, Casagrande C, Tjonneland A, Olsen A, Overvad K, ThorlaciusUssing O, Clavel-Chapelon F, Boutron-Ruault MC, Morois S, Kaaks R, Linseisen J, Boeing H, Nöthlings U, Trichopoulou A, Trichopoulos D, Misirli G, Palli D, Sieri S, Panico S, Tumino R, Vineis P, Peeters PH, van Gils CH, Ocké 
$M C$, Lund $\mathrm{E}$, et al: Fruit, vegetables, and colorectal cancer risk: the European Prospective Investigation into Cancer and Nutrition. Am J Clin Nutr 2009, 89:1441-1452

9. Murphy N, Norat T, Ferrari P, Jenab M, Bueno-de-Mesquita B, Skeie G, Dahm CC, Overvad K, Olsen A, Tjonneland A, Clavel-Chapelon F, Boutron-Ruault MC, Racine A, Kaaks R, Teucher B, Boeing H, Bergmann MM, Trichopoulou A, Trichopoulos D, Lagiou P, Palli D, Pala V, Panico S, Tumino R, Vineis P, Siersema $P$, van Duijnhoven F, Peeters PH, Hjartaker A, Engeset D, et al: Dietary fibre intake and risks of cancers of the colon and rectum in the European prospective investigation into cancer and nutrition (EPIC). PLoS One 2012, 7:e39361.

10. Murphy $N$, Norat $T$, Ferrari $P$, Jenab M, Bueno-de-Mesquita B, Skeie $G$, Olsen A, Tjonneland A, Dahm CC, Overvad K, Boutron-Ruault MC, Clavel-Chapelon F, Nailler L, Kaaks R, Teucher B, Boeing H, Bergmann MM, Trichopoulou A, Lagiou P, Trichopoulos D, Palli D, Pala V, Tumino R, Vineis P, Panico S, Peeters PH, Dik VK, Weiderpass E, Lund E, Garcia JR, et al: Consumption of dairy products and colorectal cancer in the European Prospective Investigation into Cancer and Nutrition (EPIC). PLoS One 2013, 8:e72715.

11. Gonzalez CA, Riboli E: Diet and cancer prevention: contributions from the European Prospective Investigation into Cancer and Nutrition (EPIC) study. Eur J Cancer 2010, 46:2555-2562.

12. Leufkens AM, Van Duijnhoven FJ, Siersema PD, Boshuizen HC, Vrieling A, Agudo A, Gram IT, Weiderpass E, Dahm C, Overvad K, Tjønneland A, Olsen A, Boutron-Ruault MC, Clavel-Chapelon F, Morois S, Palli D, Grioni S, Tumino R, Sacerdote C, Mattiello A, Herman S, Kaaks R, Steffen A, Boeing $H_{\text {, }}$ Trichopoulou A, Lagiou P, Trichopoulos D, Peeters PH, van Gils CH, van Kranen $\mathrm{H}$, et al: Cigarette smoking and colorectal cancer risk in the European Prospective Investigation into Cancer and Nutrition study. Clin Gastroenterol Hepatol 2011, 9:137-144

13. Friedenreich $C$, Norat $T$, Steindorf $K$, Boutron-Ruault MC, Pischon T, Mazuir M, Clavel-Chapelon F, Linseisen J, Boeing H, Bergman M, Johnsen NF, Tjønneland A, Overvad K, Mendez M, Quirós JR, Martinez C, Dorronsoro M, Navarro C, Gurrea AB, Bingham S, Khaw KT, Allen N, Key T, Trichopoulou A, Trichopoulos D, Orfanou N, Krogh V, Palli D, Tumino R, Panico S, et al: Physical activity and risk of colon and rectal cancers: the European prospective investigation into cancer and nutrition. Cancer Epidemiol Biomarkers Prev 2006, 15:2398-2407.

14. World Cancer Research Fund/American Institute for Cancer Research: Continuous Update Project Report. Food, Nutrition, Physical Activity, and the Prevention of Colorectal Cancer. 2011.

15. Wiseman M: The second World Cancer Research Fund/American Institute for Cancer Research expert report. Food, nutrition, physical activity, and the prevention of cancer: a global perspective. Proc Nutr Soc 2008, 67:253-256

16. World Cancer Research Fund/American Institute for Cancer Research: Food, Nutrition, Physical Activity, and the Prevention of Cancer: a Global Perspective. Washington DC: AICR; 2007.

17. Eide GE, Heuch I: Average attributable fractions: a coherent theory for apportioning excess risk to individual risk factors and subpopulations. Biom J 2006, 48:820-837.

18. Aleksandrova K, Nimptsch K, Pischon T: Obesity and colorectal cancer. Front Biosci 2013, 5:61-77.

19. Robsahm TE, Aagnes B, Hjartaker A, Langseth H, Bray FI, Larsen IK: Body mass index, physical activity, and colorectal cancer by anatomical subsites: a systematic review and meta-analysis of cohort studies. Eur J Cancer Prev 2013, 22:492-505

20. Harriss DJ, Atkinson G, Batterham A, George K, Cable NT, Reilly T, Haboubi N, Renehan AG, Colorectal Cancer Lifestyle Exercise and Research Group: Lifestyle factors and colorectal cancer risk (2): a systematic review and meta-analysis of associations with leisure-time physical activity. Colorectal Dis 2009, 11:689-701.

21. Hoffmann K, Heidemann C, Weikert C, Schulze MB, Boeing H: Estimating the proportion of disease due to classes of sufficient causes. Am J Epidemiol 2006, 163:76-83.

22. Riboli E, Hunt KJ, Slimani N, Ferrari P, Norat T, Fahey M, Charrondiere UR, Hemon B, Casagrande C, Vignat J, Overvad K, Tjønneland A, ClavelChapelon F, Thiébaut A, Wahrendorf J, Boeing H, Trichopoulos D, Trichopoulou A, Vineis P, Palli D, Bueno-De-Mesquita HB, Peeters PH, Lund E, Engeset D, González CA, Barricarte A, Berglund G, Hallmans G, Day NE, Key TJ, et al: European Prospective Investigation into Cancer and Nutrition (EPIC): study populations and data collection. Public Health Nutr 2002, 5:1113-1124.
23. Bramer GR: International statistical classification of diseases and related health problems. Tenth revision. Colorectal Dis 1988, 41:32-36.

24. World Health Organization: International classification of diseases for oncology. 2nd edition. Geneva, Switzerland; 1990.

25. Slimani N, Deharveng G, Unwin I, Southgate DA, Vignat J, Skeie G, Salvini S, Parpinel M, Moller A, Ireland J, Becker W, Farran A, Westenbrink S, Vasilopoulou E, Unwin J, Borgejordet A, Rohrmann S, Church S, Gnagnarella P, Casagrande C, van Bakel M, Niravong M, Boutron-Ruault MC, Stripp C, Tjønneland A, Trichopoulou A, Georga K, Nilsson S, Mattisson I, Ray J, et al: The EPIC nutrient database project (ENDB): a first attempt to standardize nutrient databases across the 10 European countries participating in the EPIC study. Eur J Clin Nutr 2007, 61:1037-1056.

26. Kaaks R, Riboli E: Validation and calibration of dietary intake measurements in the EPIC project: methodological considerations. European Prospective Investigation into Cancer and Nutrition. Int J Epidemiol 1997, 26:S15-S25.

27. World Health Organization: Physical status: the use and interpretation of anthropometry. Report of a WHO Expert Committee. Tech Rep Ser 1995, 854:1-452.

28. Alberti KG, Zimmet $P$, Shaw J: The metabolic syndrome-a new worldwide definition. Lancet 2005, 366:1059-1062.

29. Fieller E: The biological standardization of insulin. J R Stat Soc 1940, 7:1-15.

30. Lunn M, McNeil D: Applying Cox regression to competing risks. Biometrics 1995, 51:524-532.

31. Miettinen OS: Proportion of disease caused or prevented by a given exposure, trait or intervention. Am J Epidemiol 1974, 99:325-332.

32. Bruzzi $P$, Green SB, Byar DP, Brinton LA, Schairer C: Estimating the population attributable risk for multiple risk factors using case-control data. Am J Epidemiol 1985, 122:904-914.

33. Whittemore AS: Statistical methods for estimating attributable risk from retrospective data. Stat Med 1982, 1:229-243.

34. Ford ES, Bergmann MM, Kroger J, Schienkiewitz A, Weikert C, Boeing H: Healthy living is the best revenge: findings from the European Prospective Investigation Into Cancer and Nutrition-Potsdam study. Arch Intern Med 2009, 169:1355-1362.

35. Pischon T, Mohlig M, Hoffmann K, Spranger J, Weikert C, Willich SN, Pfeiffer $\mathrm{AF}$, Boeing $\mathrm{H}$ : Comparison of relative and attributable risk of myocardial infarction and stroke according to C-reactive protein and low-density lipoprotein cholesterol levels. Eur J Epidemiol 2007, 22:429-438.

36. Heidemann C, Hoffmann K, Klipstein-Grobusch K, Weikert C, Pischon T, Hense HW, Boeing $\mathrm{H}$ : Potentially modifiable classic risk factors and their impact on incident myocardial infarction: results from the EPIC-Potsdam study. Eur J Cardiovasc Prev Rehabil 2007, 14:65-71.

37. Zavoral M, Suchanek S, Zavada F, Dusek L, Muzik J, Seifert B, Fric P: Colorectal cancer screening in Europe. World J Gastroenterol 2009, 15:5907-5915.

38. Correa Lima MP, Gomes-da-Silva MH: Colorectal cancer: lifestyle and dietary factors. Nutr Hosp 2005, 20:235-241.

39. Ahmed FE: Effect of diet, life style, and other environmental/ chemopreventive factors on colorectal cancer development, and assessment of the risks. J Environ Sci Health C Environ Carcinog Ecotoxicol Rev 2004, 22:91-147.

40. Qasim A, O'Morain C: Primary prevention of colorectal cancer: are we closer to reality? Eur J Gastroenterol Hepatol 2010, 22:9-17.

41. Platz EA, Willett WC, Colditz GA, Rimm EB, Spiegelman D, Giovannucci E: Proportion of colon cancer risk that might be preventable in a cohort of middle-aged US men. Cancer Causes Control 2000, 11:579-588.

42. Kirkegaard H, Johnsen NF, Christensen J, Frederiksen K, Overvad K, Tjonneland A: Association of adherence to lifestyle recommendations and risk of colorectal cancer: a prospective Danish cohort study. BMJ 2010, 341:c5504.

43. Wei EK, Colditz GA, Giovannucci EL, Fuchs CS, Rosner BA: Cumulative risk of colon cancer up to age 70 years by risk factor status using data from the Nurses' Health Study. Am J Epidemiol 2009, 170:863-872.

44. Romaguera D, Vergnaud AC, Peeters PH, van Gils CH, Chan DS, Ferrari P, Romieu I, Jenab M, Slimani N, Clavel-Chapelon F, Fagherazzi G, Perquier F, Kaaks R, Teucher B, Boeing $H$, von Rüsten A, Tjønneland A, Olsen A, Dahm CC, Overvad K, Quirós JR, Gonzalez CA, Sánchez MJ, Navarro C, Barricarte A, Dorronsoro M, Khaw KT, Wareham NJ, Crowe FL, Key TJ, et al: Is concordance with World Cancer Research Fund/American Institute for Cancer Research 
guidelines for cancer prevention related to subsequent risk of cancer? Results from the EPIC study. Am J Clin Nutr 2012, 96:150-163.

45. Aleksandrova K, Nimptsch K, Pischon T: Influence of obesity and related metabolic alterations on colorectal cancer risk. Curr Nutr Repts 2013, 2:1-9.

46. Aleksandrova K, Drogan D, Boeing H, Jenab M, Bas Bueno-de-Mesquita $H$, Jansen E, van Duijnhoven FJ, Rinaldi S, Fedirko V, Romieu I, Kaaks R, Riboli E, Gunter MJ, Romaguera D, Westhpal S, Overvad K, Tjønneland A, Halkjaer J, Boutron-Ruault MC, Clavel-Chapelon F, Lukanova A, Trichopoulou A, Trichopoulos D, Vidalis P, Panico S, Agnoli C, Palli D, Tumino R, Vineis P, Buckland G, et al: Adiposity, mediating biomarkers and risk of colon cancer in the European prospective investigation into cancer and nutrition study. Int I Cancer 2014, 134:612-621.

47. Fu Z, Shrubsole MJ, Smalley WE, Wu H, Chen Z, Shyr Y, Ness RM, Zheng W: Lifestyle factors and their combined impact on the risk of colorectal polyps. Am J Epidemiol 2012, 176:766-776.

doi:10.1186/s12916-014-0168-4

Cite this article as: Aleksandrova et al: Combined impact of healthy lifestyle factors on colorectal cancer: a large European cohort study. BMC Medicine 2014 12:168.

\section{Submit your next manuscript to BioMed Central and take full advantage of:}

- Convenient online submission

- Thorough peer review

- No space constraints or color figure charges

- Immediate publication on acceptance

- Inclusion in PubMed, CAS, Scopus and Google Scholar

- Research which is freely available for redistribution 